\title{
FEM Design of Virtual Experiments for Mechanical Engineering Education
}

\author{
Yi Jiangang ${ }^{1, a}$, Xu Ping ${ }^{1, b^{*}}$ \\ ${ }^{1}$ School of Electromechanical and Architectural Engineering, Jianghan University, Wuhan, China

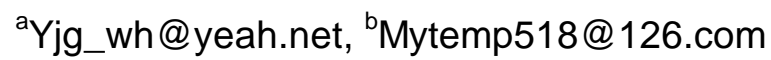

Keywords: Finite element method; Virtual experiment; Computer Simulation; College education Abstract. Comprehensive experiment design in mechanical engineering education is a key step for creative teaching in college education. In order to solve the problem, Virtual experiment approach based on FEM is proposed. Through modeling, simulation and calculation of the vertical drill, the design process of the virtual experiment is illustrated. Compared with traditional experiment teaching, students' innovative thinking and innovative ability are improved by using the proposed approach.

\section{Introduction}

How to design innovative experiments is one of the key factors for improving mechanical engineering students' creative ability in college education. However, many mechanical engineering curriculums are subject to many fields, such as machine, electricity, liquid, control, computer and so on, which makes it difficult to carry out comprehensive experimental teaching. To solve this problem, the virtual experiment design based on finite element method (FEM) is proposed to help students' innovative thinking, and therefore to improve their creative ability.

\section{Modeling of Virtual Experiments Design}

In traditional experimental courses of mechanical engineering education, much time is used for Narrative introduction and demonstration. Students have few chances to design experiments themselves. On the other hand, the lack of laboratory equipments and tools often restricts the implementation of comprehensive experiment teaching. Therefore, the design of virtual experiments based on FEM is researched in this paper.

Vertical drill is the typical machine in mechanical engineering curriculums. It is widely used in machine working line for producing holes in hard substances. Because of the high rotating speed in the drilling process, the vertical drill spindle is subjected to a great deal of stresses, such as bending stresses and twisting stresses. Therefore, the metal fatigue of the spindle is the main problem for vertical drill maintenance. If the metal fatigue sign cannot be detected in good time, it may cause spindle fracture, or even lead to grave worksite accidents. For the purpose of illustrating design process of virtual experiments, the vertical drill is used as the sample.

The typical vertical drill is driven by motor through drive belts. The drive belts are connected with the drill spindle wheel and the motor spindle, and have vibratory absorption function when drilling. Because $\mathrm{V}$ belt allows large transmission ratio with compact structure, $\mathrm{V}$ belt wheel is chosen in the vertical drill. The structure of the drill spindle is shown in Fig. 1, which is supported at two points. One point is at the left end which is fixed in the drill, the other point is at the right end which can be moved for drilling.

According to the theory of elastic-plastic distortion, there should satisfy the following relations for drilling mechanical properties:

$$
\frac{\mathrm{n}_{\max }}{\mathrm{n}_{\mathrm{er}}}=\frac{2 \mathrm{R}}{D}
$$

Where $\mathrm{D}$ is the bit diameter, $\mathrm{R}$ is the radius of the spindle, $n_{\max }$ is the maximum rotation speed, and $n_{e r}$ is the rated rotation speed. 


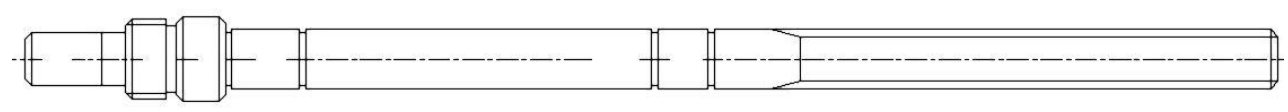

Fig. 1 The spindle structure

To determine the stress of the drill, it is necessary to calculate the rated power on the drill spindle, which is given by equation (2).

$$
\mathrm{N}=\mathrm{K} \frac{T v}{1000 \eta}
$$

Where $\mathrm{N}$ is the rated power, $\mathrm{K}$ is the friction and plastic bending influence coefficient, $\mathrm{T}$ is the twisting tension, $v$ is the drilling speed, and $\eta$ is the transmission efficiency.

From equation (1) and (2), it can be concluded that the stress of the drill spindle is mainly related to drill speed. Therefore, the determination of the spindle stress is the precondition of the strength calculation of the bit and other components. In general, the spindle stress is mainly influenced by the following factors:

(1) The drilling speed;

(2) The materials of drilling and their states;

(3) The drilling feed rate;

(4) The diameter of drilling hole.

\section{Simulation of the spindle}

Because the above factors are very difficult to analyze in the theoretical method, this paper applies the approach of finite element simulation. The 3D model of the drill spindle is established by using UG software. According to the working parameters, the stress distribution can be simulated, as shown in Fig. 2. It is found after simulation that the maximum bending stress distribution position is at the head of the spindle and in the middle of the tail, and the max twisting stress distribution position is at the connection position of the tail and the head of the spindle. In the continuous rolling process, the twisting force is gradually increased with the impact of the bending force. However, the technical requirements of the drilling process need to make the stress constant, that is, the stress will not change with the increase speed of the drill. As the result, the speed of the drill should be adjusted to adapt to the change of the stress. Therefore, the following two factors should be considered in drilling speed control:

(1) The spindle driving torque should not be influenced when adjusting the drilling speed to adapt to the stress change;

(2) To meet the stress change and the adjustment of the spindle speed, tension fluctuations should be considered.

(3) The impact force should be avoided when drilling, which greatly influences the change of the twisting stress at the drill spindle. 


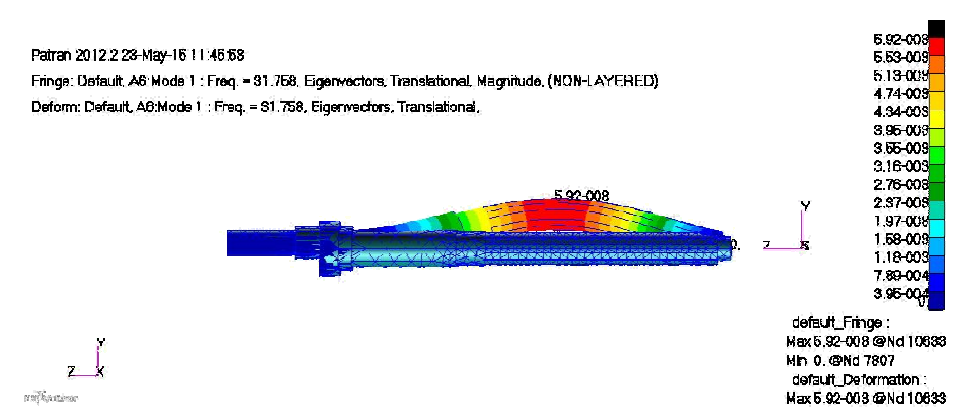

(a) Tail bending stress

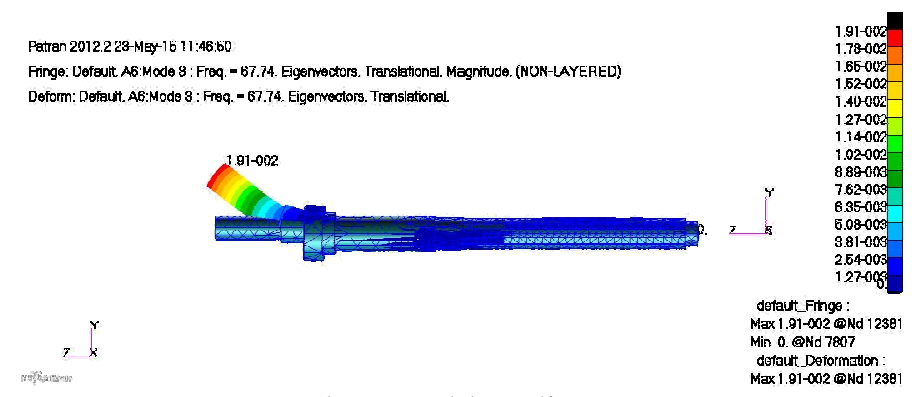

(b) Head bending stress

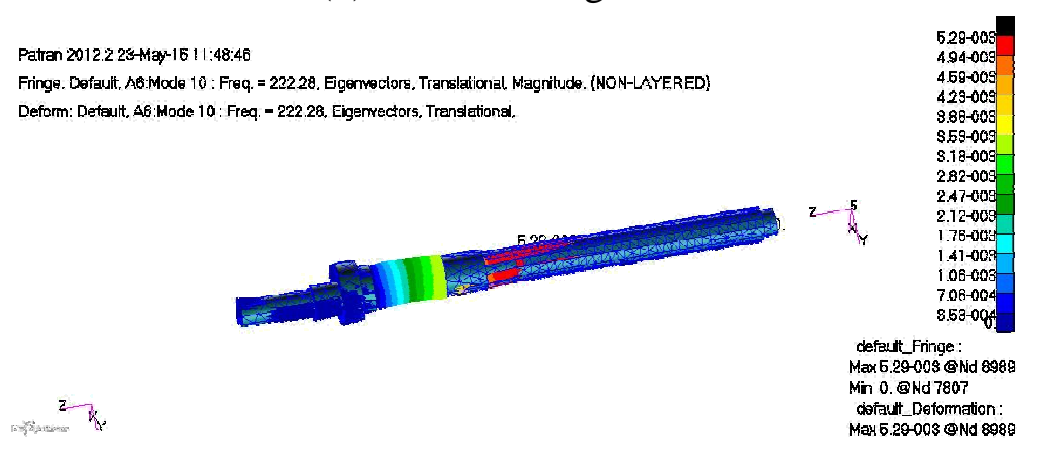

(c) Twisting stress

Fig.2 Simulation of the drill spindle

\section{Analysis of the ecentric shaft}

In the drilling process, the tail of the spindle is connected to ecentric shaft for other uses. When using ecenric shaft, the force of the spindle is more complex because there is an additional bending and twisting composite force, as shown in Fig. 3. To analyze the stress distribution of the eccentric shaft, its 3D model is established, as shown in Fig. 4. After simulation, it can be found that the stress focus point is at the connection position of the eccentric and the spindle. Because the eccentric force of speeding drill, there is a downward pressure on the sector block. With the increasing of the speed, the radial pressure on the shaft is greatly increasing. In this case, plastic deformation is produced in the spindle. In addition, the pressure on the shaft will be too high to discharge the drilled material. Therefore, it is important to pay attention to check the connection position of the spindle and the eccentric shaft. By using theoretical analysis, computer simulation and finite element method for the drilling process, the stress distribution experiment of the mechanism provides guidance for mechanical engineering students.. 


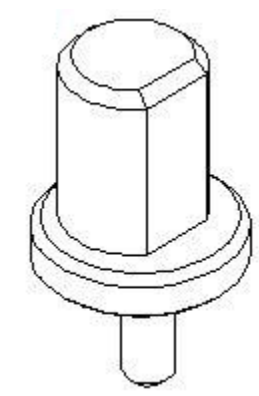

Fig.3 The ecentric shaft

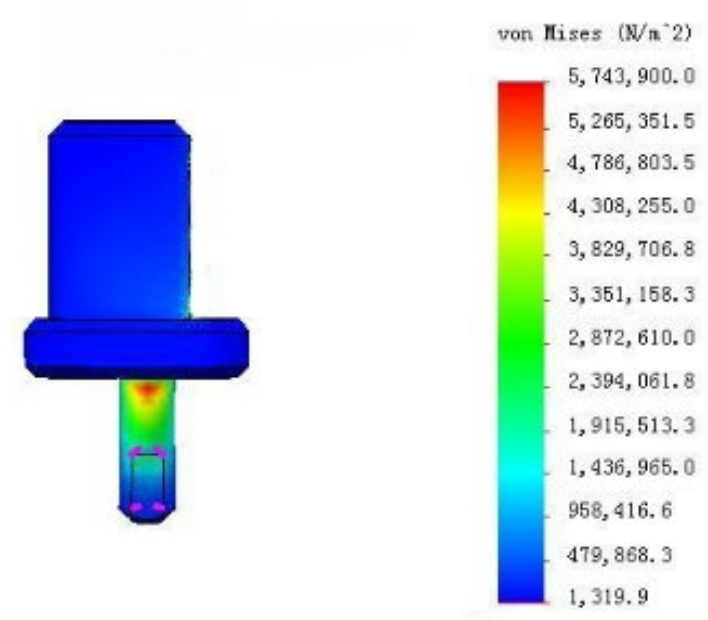

Fig. 4 Stress distribution of the ecentric shaft

\section{Conclusions}

Because of the flexible configuration ability of virtual experiments, students can design and calculate complex mechanical device model without much cost of money and time. In this case, by using FEM computer software, students' innovative thinking can be developed, which is more important than the study of the experiment.

\section{Acknowledgements}

This work is supported by Wuhan Engineering Research Center of Complex Electromechanical System, China. The authors also gratefully acknowledge the helpful comments and suggestions of the reviewers, which have improved the presentation.

\section{References}

[1] Ho, T.H. and K.K. Ahn, Modeling and simulation of hydrostatic transmission system with energy regeneration using hydraulic accumulator. Journalof Mechanical Scienceand Technology, Vol.24 (2010), p. 1163-1175

[2] Khlaief Amor, Boussak Mohamed, Gossa Moncef. Model reference adaptive system based adaptive speed estimation for sensorless vector control with initial rotor position estimation for interior permanent magnet synchronous motor drive, Electric Power Components and Systems, Vol. 41 (2013), p. 47-74.

[3] Yi Jiangang. Modelling and Analysis of Step Response Test for Hydraulic Automatic Gauge Control, Strojniški vestnik - Journal of Mechanical Engineering, Vol. 61 (2015), p. 115-122. 
[4] Kim, H.E., G.C. Lee and J.H. Kim, System design and performance test of hydraulic intensifier. Transactions of the Korean Society of Mechanical Engineers, Vol.34 (2010), p. 947-952.

[5] Truong Dinh Quang, Ahn Kyoung Kwan, Force control for hydraulic load simulator using self-tuning grey predictor-fuzzy PID, Mechatronics, Vol.19 (2009), p.233-246.

[6] Cheng Nan, Zhu Yan-Zhi. Optimal sequencing and scheduling of middle-sized hydroelectric stations based on fuzzy integral weighting integer programming. System Engineering Theory and Practice, Vol.28 (2008), p. 122-128. 